University of Nebraska - Lincoln

DigitalCommons@University of Nebraska - Lincoln

\title{
Comparative growth of spring-planted canola, brown mustard and camelina
}

\author{
A. D. Pavlista \\ University of Nebraska, PREC, Scottsbluff, NE, apavlista@unl.edu \\ D. D. Baltensperger \\ Texas A\&M University, College Station, dbaltensperger@tamu.edu \\ T. A. Isbell \\ USDA-ARS, Peoria, IL, Terry.Isbell@ars.usda.gov \\ G. W, Hergert \\ University of Nebraska, PREC, Scottsbluff, NE, ghergert1@unl.edu
}

Follow this and additional works at: https://digitalcommons.unl.edu/panhandleresext

Part of the Agriculture Commons

Pavlista, A. D.; Baltensperger, D. D.; Isbell, T. A.; and Hergert, G. W, "Comparative growth of spring-planted canola, brown mustard and camelina" (2012). Panhandle Research and Extension Center. 53.

https://digitalcommons.unl.edu/panhandleresext/53

This Article is brought to you for free and open access by the Agricultural Research Division of IANR at DigitalCommons@University of Nebraska - Lincoln. It has been accepted for inclusion in Panhandle Research and Extension Center by an authorized administrator of DigitalCommons@University of Nebraska - Lincoln. 


\title{
Comparative growth of spring-planted canola, brown mustard and camelina
}

\author{
A.D. Pavlista ${ }^{\mathrm{a}, *}$, D.D. Baltensperger ${ }^{\mathrm{b}}$, T.A. Isbell ${ }^{\mathrm{c}}$, G.W. Hergert ${ }^{\mathrm{a}}$ \\ a University of Nebraska, PREC, Scottsbluff, NE 69361, USA \\ b Texas AEM University, College Station, TX 77843, USA \\ ${ }^{\text {c } U S D A-A R S, ~ P e o r i a, ~ I L ~ 61604, ~ U S A ~}$
}

\section{A R T I C L E I N F O}

\section{Article history:}

Received 2 March 2011

Received in revised form 18 July 2011

Accepted 20 July 2011

Available online 28 September 2011

\section{Keywords:}

Nebraska Panhandle

Oilseed crops

Fatty acids

Biofuel

\begin{abstract}
A B S T R A C T
With increased emphasis for diesel substitution, production of brown mustard (Brassica juncea), canola (Brassica napus) and camelina (Camelina sativa) used as biodiesels may increase in the High Plains. Since these are new crops to this region, understanding their growth is critical for their acceptance. The objective was to elucidate the growth pattern of these crops when spring-planted in western Nebraska. Field trials were conducted in 2005, 2006 and 2007 with early May planting. Plots were seeded $2 \mathrm{~cm}$ deep at 200 plants $\mathrm{m}^{-2}$. Four plants were destructively sampled at about 28, 40, 53, 61, and 82 days after planting (DAP). Canopy growth was field measured. Canopy heights peaked by 61 DAP at 95,85 and $70 \mathrm{~cm}$ for brown mustard, canola and camelina, respectively. Stem length increased to 82 DAP at the rates of $1.24,1.22$ and $0.85 \mathrm{~cm} / \mathrm{d}$ for brown mustard, canola and camelina, respectively. Root weight accumulated linearly from 28 to 61 DAP. The Brassica grew roots faster and achieved higher weights than camelina. From 28 to 40 DAP, vine fresh weight accumulated rapidly for these crops, leveled and then gradually declined as leaves desiccated. Vine dry weight increased to 61 DAP and then plateaued. The maximum vine dry weights, reached at $61 \mathrm{DAP}$, were $4.3,4.5$ and $3.0 \mathrm{~g} / \mathrm{plant}$ for brown mustard, canola and camelina, respectively. By 61 DAP, pods were present and accumulated dry matter while leaves senesced. Pod fresh weight reached its peak at 61 DAP while its dry weight increased linearly to 82 DAP at rates of $0.36,0.24$ and $0.096 \mathrm{~g} / \mathrm{d}$ for brown mustard, canola and camelina, respectively. Harvest in 2006 showed no significant $(p<0.05)$ difference between crops with a mean yield of about $1500 \mathrm{~kg} \mathrm{ha}^{-1}$. Fatty acid composition was dramatically different between the crops as previously reported. The growth patterns of these crops indicated that all three would be suitable for production in the northern High Plains.
\end{abstract}

(C) 2011 Elsevier B.V. All rights reserved.

\section{Introduction}

Oilseed crops are relatively new crops to the High Plains, primarily grown for vegetable and industrial oils, spices and bird feed (Meyer et al., 1999). With increased fuel concerns, there is an expanded demand for bio-diesel substitutes (Dyer et al., 2008). Hectares of oilseed crops, e.g., brown mustard, canola and camelina can be increased in the High Plains to help fulfill this demand (Pavlista et al., 2011b). Studies on these crops as bio-diesel sources had shown potential in the region. Although there were production guides for brown mustard (Baltensperger et al., 2004) and canola (Boyles et al., 2006), datasets on their growth and development are minimal (Johnston et al., 2002) or generalized (Ludlow and Muchow, 1990). Climatic impact data on their life cycle also are minimal (Angadi et al., 2000). An understanding of the adaptability of these crops to climate depends on characterizing their development for spring planting (Pavlista et al., 2011a). Brown

\footnotetext{
* Corresponding author.

E-mail address: apavlista@unl.edu (A.D. Pavlista).
}

mustard, canola and camelina are new crops to the semi-arid region called the High Plains, western and central NE, eastern WY, western KS, eastern CO, and the Panhandle of TX (Clark and Scheiber, 2008). Nebraska and Kansas need alternate crops to rotate with wheat. Determining the growth patterns of these crops will assist with their acceptance as 'new' oilseed crops in this region. Understanding adaptability and growth of these crops is critical for their introduction into the High Plains (Pavlista et al., 2011b). Therefore, the specific objective of this study was to collect growth pattern data on brown mustard, canola and camelina for production in the northern High Plains. These data along with that on spring planting dates (Pavlista et al., 2011a) will assist in presenting the foundation for agronomic development of these crops in this region.

\section{Materials and methods}

Field trials were conducted in 2005, 2006 and 2007 on brown mustard cv. Arid, canola cv. Hyola 401 and camelina cv. Boa at the Panhandle Research \& Extension Center, Scottsbluff, NE $\left(41^{\circ} 50^{\prime} \mathrm{N}\right.$, $103^{\circ} 41^{\prime} \mathrm{W}$, elevation $1208 \mathrm{~m}$ ). Soil was a Tripp fine sandy loam at $\mathrm{pH} 7.8$ and organic matter content of $0.9 \%$. Weather information 
Table 1

Air temperature from April to July at Scottsbluff, NE, in 2005, 2006 and 2007 including deviation from long-term averages.

\begin{tabular}{|c|c|c|c|c|c|c|}
\hline & \multicolumn{2}{|c|}{2005} & \multicolumn{2}{|c|}{2006} & \multicolumn{2}{|l|}{2007} \\
\hline & ${ }^{\circ} \mathrm{C}$ & Dev. ${ }^{a}$ & ${ }^{\circ} \mathrm{C}$ & Dev. & ${ }^{\circ} \mathrm{C}$ & Dev. \\
\hline April & - & - & - & - & 7.4 & -1.3 \\
\hline May & 13.1 & -1.3 & 19.4 & -0.5 & 23.9 & 0.7 \\
\hline June & 15.1 & 0.7 & 22.1 & 2.2 & 24.5 & 1.3 \\
\hline July & 15.2 & 0.9 & 20.8 & 0.9 & 25.0 & 1.8 \\
\hline
\end{tabular}

a Deviation from the long-term average.

was collected from a weather station located next to the field monitored by the High Plains Climate Center (Changnon et al., 1990). Rainfall was supplemented with an overhead, linear-move, sprinkler system to achieve equivalent water availability for all three years. Between emergence and the last growth readings, total rainfall plus irrigation was 193, 188, and $183 \mathrm{~mm}$ for 2005, 2006, and 2007, respectively. May and June of 2005 were cooler than the longterm average while July was near normal (Pavlista et al., 2011a). The growing seasons of 2006 and 2007 were similar and tended to be warmer than the long-term average (Table 1 ).

Plots were comprised by four rows, each $0.3 \mathrm{~m}$ wide and $4.6 \mathrm{~m}$ long. Planting dates for the three crops were 6 May 05, 11 May 06, and 9 May 07. Vigil et al. (1997) recommended that canola be planted when soil temperatures were sustained at $8{ }^{\circ} \mathrm{C}$ or greater; this is typically reached the last week of April to the beginning of May in western NE. Samples of four plants from plots were sacrificed for measuring growth from around 28 to 82 DAP (Table 2). Plant emergence in each plot was visually estimated by two people three times a week for the first three weeks after planting. Canopy height and width were measured in the field using a meter stick at four places in each plot and averaged. Percent row closure, leaf senescence and defoliation were visually estimated in the field by two people independently for each plot. Four plants were dug to $30 \mathrm{~cm}$ and removed from each plot at 28, 40,61, and 82 DAP. The plants were cut at the soil line. The roots at 28, 40 and 61 DAP were rinsed to remove soil, damp dried with paper toweling and weighed. Main stem length was measured on the lab counter with a meter stick. The number of nodes with leaves on the main stem were counted and referred to as leaf node number. Vine weights were measured as the top vegetative growth, i.e., excluding pods. Pods did not appear until 61 DAP and measured separately from the stem plus branches plus leaves ('vine'). Dry weights were measured after the plant parts were in a drier for several days at $49^{\circ} \mathrm{C}$. In 2005 and 2006, plots were harvested for seed on 5 and 4 August, respectively. But, in 2005, seed yields were very low due to bird damage and crops could not be compared well. Plots were not harvested in 2007 due to mechanical difficulties with the combine. Fatty acid and oil content analyses were conducted on seed harvested in 2006 according to Pavlista et al. (2011b). A randomized complete block design with three replications was used in all trials and the data were analyzed using Proc ANOVA (SAS Inst., 2003).

\section{Table 2}

Dates and days after planting of growth readings for crop comparisons at Scottsbluff, NE.

\begin{tabular}{lllccrr}
\hline 2005 & 2006 & 2007 & 2005 & 2006 & 2007 & Mean \\
\hline \multicolumn{2}{l}{ Date of readings } & & \multicolumn{2}{c}{ Days after planting (DAP) } \\
\hline 6 May & 11 May & 9 May & 0 & 0 & 0 & 0 \\
20 May & 25 May & 23 May & 14 & 14 & 14 & 14 \\
6 June & 6 June & 6 June & 31 & 26 & 28 & 28 \\
17 June & 16 June & 19 June & 42 & 36 & 41 & 40 \\
1 July & 30 June & 2 July & 56 & 50 & 54 & 53 \\
8 July & 7 July & 12 July & 63 & 57 & 64 & 61 \\
27 July & 31 July & 2 August & 82 & 81 & 83 & 82 \\
\hline
\end{tabular}
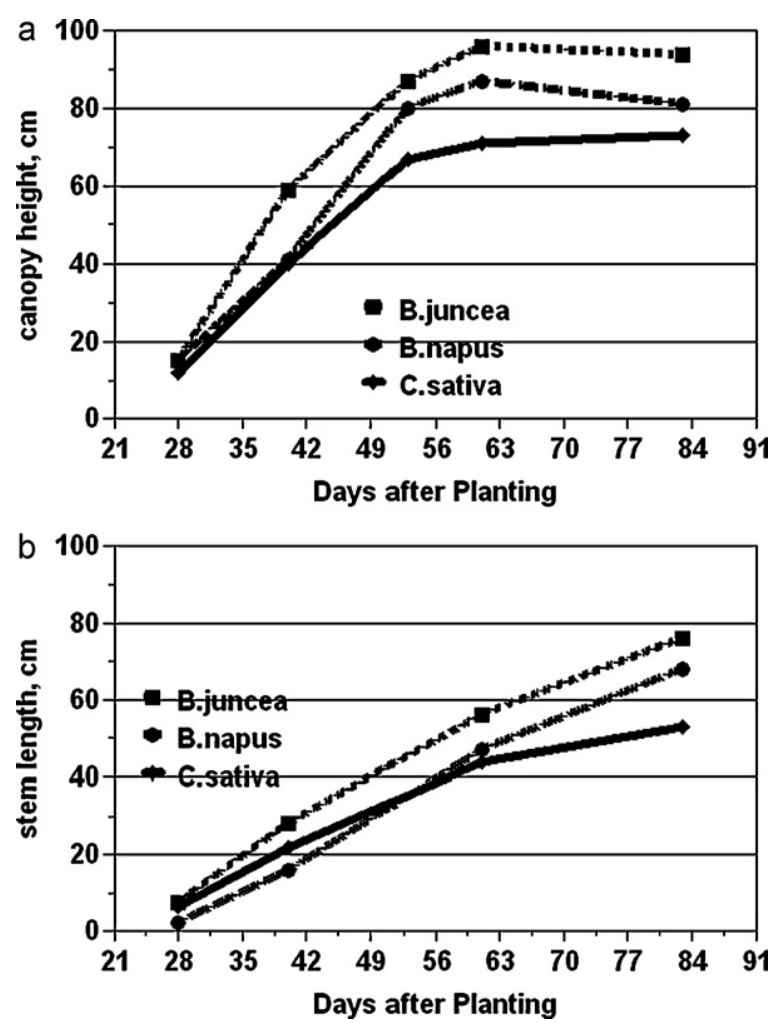

Fig. 1. Growth of canopy height and stem length from 28 to 82 DAP of brown mustard, canola and camelina at Scottsbluff, NE. Each data point is the mean of 2005 , 2006 and 2007, three years. The LSD $_{0.05}$ for canopy heights was 2, 5, 6, 11, and 6 for $28,40,53,61$, and 82 DAP, respectively, and for stem length, they were $1,3,3$, and 4 for $28,40,61$, and 82 DAP, respectively.

Data were presented as means of three years except for yield and oil content. Means were separated by least significant differences and are reported as significant at $p<0.05$ or $95 \%$ confidence level. Growth curves were analyzed using regression.

Imidacloprid (Merit at 2.5 $\mathrm{L} \mathrm{ha}^{-1}$ ) and bifenthrin (Capture 2EC at $0.1 \mathrm{Lha}^{-1}$ ) was applied for fleabeetle (Phyllotreta spp.) control in 2006 and 2007, respectively. In 2006, plants were grown under netting to minimize bird damage primarily by house finch (Carppodacus mexicanus), and in 2007 , boom boxes playing rap music, as opposed to other musical types, were effective in June but not in late July. Weed control was obtained by pre-plant incorporation of trifluralin (Treflan $4 \mathrm{~L}$ at $1.6 \mathrm{~L} \mathrm{ha}^{-1}$ ). No fungicides needed to be applied. Urea (21-0-0) was broadcasted onto plots in March to achieve $45 \mathrm{~kg} \mathrm{~N} / \mathrm{ha}$.

\section{Results}

Emergence occurred by 7DAP and reached a maximum by 14 DAP for all three crops in all three years. Canopy height was measured from 28 to $82 \mathrm{DAP}$ (Table 2) and reached its peak for the three crops by 61 DAP (Fig. 1a). Brown mustard initially grew faster than the other two crops and produced the tallest canopy at $90-95 \mathrm{~cm}$. Canola reached a height of $80-85 \mathrm{~cm}$. Canopy height of camelina leveled at $70 \mathrm{~cm}$. Stem length increased linearly between 28 and 82 DAP (Fig. 1b). The rates of elongation were $1.24 \mathrm{~cm} / \mathrm{d}$ for brown mustard, $1.22 \mathrm{~cm} / \mathrm{d}$ for canola and $0.85 \mathrm{~cm} / \mathrm{d}$ for camelina based on linear regression analysis. Although the final stem length of brown mustard and canola was significantly different, their respective rates of elongation were not. Camelina, on the other hand, was significantly shorter and grew significantly slower than the two Brassica species. Leaf node number on the main stem below reproductive branches peaked at $40 \mathrm{DAP}$ and camelina had many more 

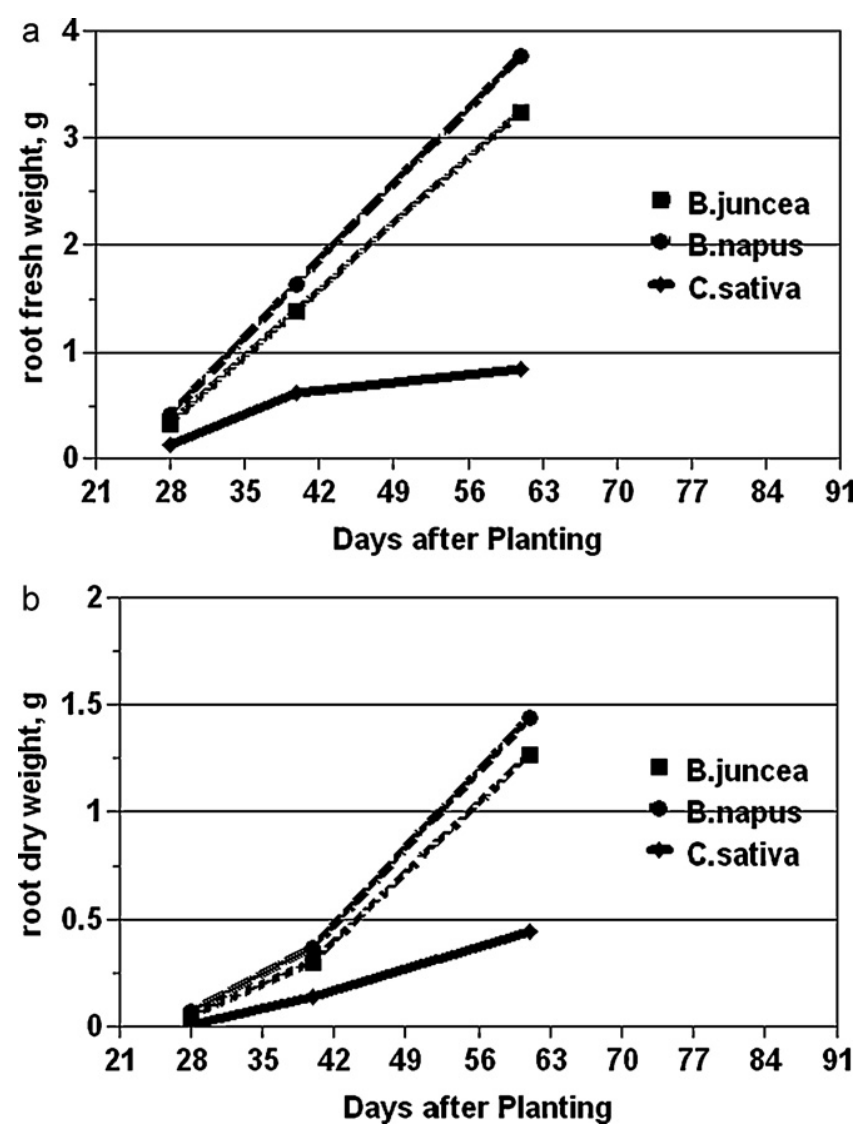

Fig. 2. Changes in root fresh and dry weights from 28 to 61 DAP of brown mustard, canola and camelina at Scottsbluff. Each data point is the mean of 2005, 2006 and 2007 , three years. The $\mathrm{LSD}_{0.05}$ for root fresh weights was $0.06,0.3$, and 0.6 for 28,40 , and 61 DAP, respectively, and for root dry weights, they were $0.02,0.07$, and 0.2 for 28,40 , and 61 DAP, respectively.

leaves ( $>20$ ) than the Brassica (9 leaves). Leaf senescence and defoliation began to be observed by 61 DAP and about half the leaves of the three crops were senesced by 83 DAP. The canopies showed a gradual widening between 28 and 53 DAP by which time percent row closure had reached a plateau for each crop. Row closure in canola was $100 \%$; for brown mustard, it was slightly less at near $90 \%$, and for camelina, rows did not close well with around $65 \%$ ground coverage.

As observed by fresh and dry weights, roots grew little during the first four weeks after planting. But from 28 to 61 DAP, linear weight increases were observed (Fig. 2a and b). There was no significant difference between the two Brassica. Dry matter accounted for about $22 \%$ and $39 \%$ of fresh weight at 40 and 61 DAP, respectively. Root fresh weight increased for the Brassica at 0.09-0.1 g/day reaching 3.2-3.8 g/plant after 61 days from planting. Camelina roots grew slower, $0.02 \mathrm{~g} / \mathrm{d}$ and only attained about $1 \mathrm{~g}$ fresh weight/plant at 61 DAP (Fig. 2a). By 61 DAP, root weights could not be accurately measured due to breakage and entanglements with roots of neighboring plants in the ground.

Vine fresh weight, excluding pods, significantly increased up to 40 DAP then plateaued to 61 DAP followed by a gradual loss of fresh weight (Fig. 3a). Dry weight, on the other hand, increased linearly to 61 DAP and then plateaued for each crop (Fig. 3b). The difference between fresh versus dry weight curves suggested the onset and gradual progression of leaf senescence and defoliation. Noted was the greater fresh weight of canola, $30 \mathrm{~g} / \mathrm{plant}$, compared to brown mustard, $19 \mathrm{~g} /$ plant, both of which were significantly heavier than camelina, $11 \mathrm{~g} /$ plant. The crops showed a similar pattern of dry weights at 83 DAP of $5.0,3.8$, and $2.8 \mathrm{~g} /$ plant
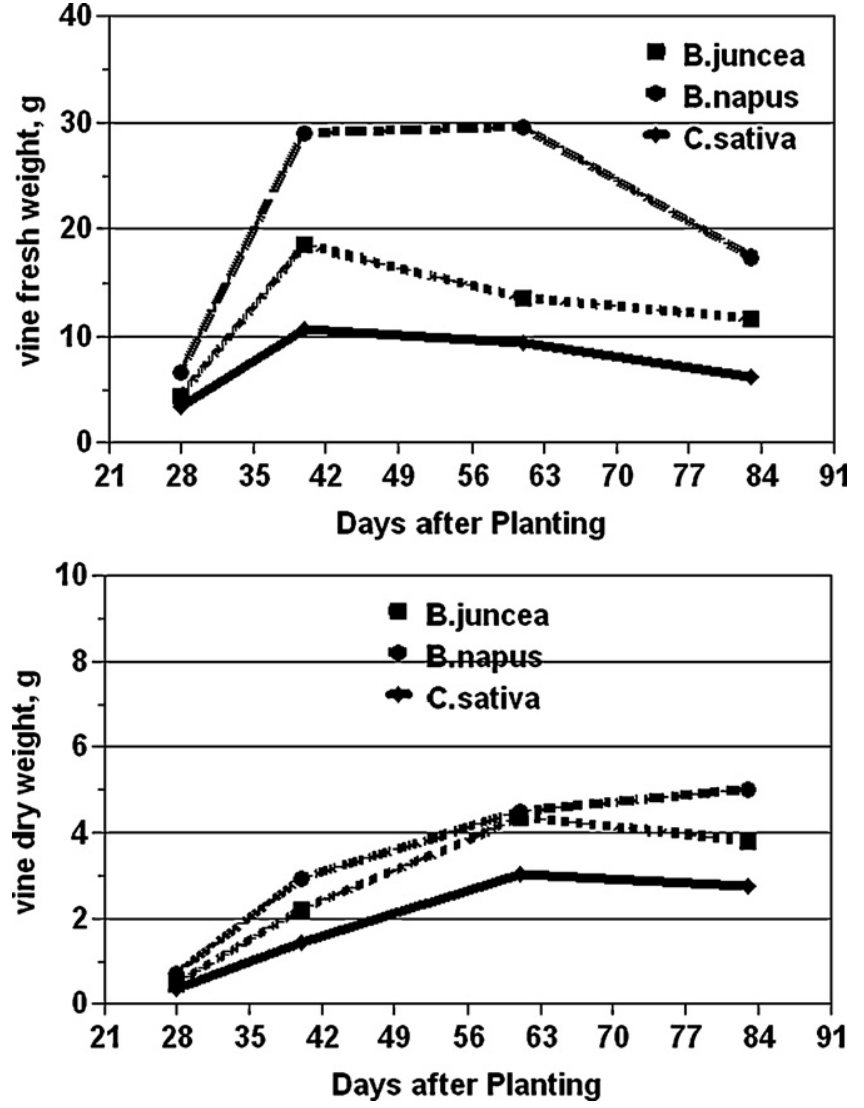

Fig. 3. Changes in vine fresh and dry weights from 28 to 82 DAP of brown mustard, canola and camelina at Scottsbluff. Each data point is the mean of 2005, 2006 and 2007 , three years. The $\mathrm{LSD}_{0.05}$ for vine fresh weights was $0.9,5,7$, and 6 for 28,40 , 61 , and 82 DAP, respectively, and for vine dry weights, they were $0.1,0.5,1.6$, and 2.0 for $28,40,61$, and 82 DAP, respectively.

for canola, brown mustard and camelina, respectively. Flowers and pods (fruit) began to appear about 40 DAP and accumulated fresh weight rapidly to 61 DAP (Fig. 4a). Although pod fresh weight for all three crops ceased to increase after 61 DAP, pod dry weight continued increasing as seeds gained dry matter (Fig. 4b). Rate of dry matter accumulation in brown mustard pods was $0.36 \mathrm{~g} / \mathrm{d}$; in canola, it was $0.24 \mathrm{~g} / \mathrm{d}$, and in camelina, it was much slower at $0.096 \mathrm{~g} / \mathrm{d}$. The gradual loss of wet weight of pods was indicative of maturation and desiccation. When adding pod weight to vine weight at 61 and $83 \mathrm{DAP}$, the result was the total aboveground weight of the plants. Fresh weight of the crops increased to a maximum at 63 DAP and the vine senescence caused a loss of water. Dry weight of the crops, on the other hand, continued to significantly increase as dry matter accumulated in the seed.

In 2006, yields for the three crops averaged 1700, 1600 and $1200 \mathrm{~kg} \mathrm{ha}^{-1}$ for brown mustard, canola and camelina, respectively, and did not significantly differ $(p=0.2)$. Oil as a percent of the dry weight of seed was significantly highest with canola at $38.9 \%$ followed by brown mustard with $36.5 \%$ and then camelina with $31.8 \%$. For the two Brassica, the major fatty acid was C18:1 (mostly oleic acid) comprising $68.0 \%$ of the oil in canola and $61.7 \%$ in brown mustard (Table 3 ). Camelina seed contained about $16.2 \%$ of $\mathrm{C} 18: 1$. The major fatty acids in camelina were $\mathrm{C} 18: 3$ (linolenic acid or 'omega3') comprising $31.0 \%$ of the oil and C18:2 (linoleic acid) comprising 21.6\% (Table 3). The brassica also contained substantial amounts of $118: 2$ comprising $15.8 \%$ of the oil from canola and $19.0 \%$ from brown mustard. 
Table 3

Fatty acid profile of brown mustard, canola and camelina, Scottsbluff, NE, in 2005 and 2006.

\begin{tabular}{|c|c|c|c|c|c|c|c|c|c|}
\hline & C $16: 0$ & C $18: 0$ & C $18: 1$ & C $18: 2$ & C $18: 3$ & C 20:0 & C $20: 1$ & C $20: 2$ & C $22: 1$ \\
\hline & \multicolumn{9}{|c|}{$\%$ total oil } \\
\hline B. juncea & 4.0 & 2.3 & 61.7 & 19.0 & 9.0 & 0.8 & 1.2 & 0 & 0.4 \\
\hline B. napus & 3.8 & 2.7 & 68.0 & 15.8 & 6.8 & 0.9 & 1.1 & 0 & 0 \\
\hline C. sativa & 6.0 & 2.5 & 16.2 & 21.6 & 31.0 & 2.0 & 12.0 & 1.7 & 3.1 \\
\hline $\operatorname{LSD}_{0.05^{\mathrm{a}}}$ & 0.1 & 0.1 & 2.2 & 1.2 & 1.2 & 0.1 & 0.5 & 0.9 & 0.6 \\
\hline
\end{tabular}

a The $p$ values for these fatty acids were less than 0.01 .

\section{Discussion}

Growth patterns of canola, brown mustard and camelina have not been reported well in the literature. Most studies relate reproductive development and seed yield to periods of water and temperature stress (Angadi et al., 2000, 2004; Chen et al., 2005; Saseendran et al., 2010). In 2005, 2006 and 2007, the growth patterns of these crops were observed from emergence to 82 DAP at Scottsbluff, NE. Canopy height leveled at 61 DAP for all three with brown mustard being the tallest and camelina the shortest. Data and the model reported by Saseendran et al. (2010) for canola cv. Hyola (sic), indicated that plant height reached a maximum at 70 DAP in 2005 and at 60 DAP in 2006 after which it remained unchanged. As canopy height increased at Scottsbluff, canopy width increased reaching a plateau around 53 DAP when the final level of row closure was observed. Camelina had the least row closure despite having more than twice as many leaves. Camelina's leaves, however, were much smaller than the Brassica which nearly closed
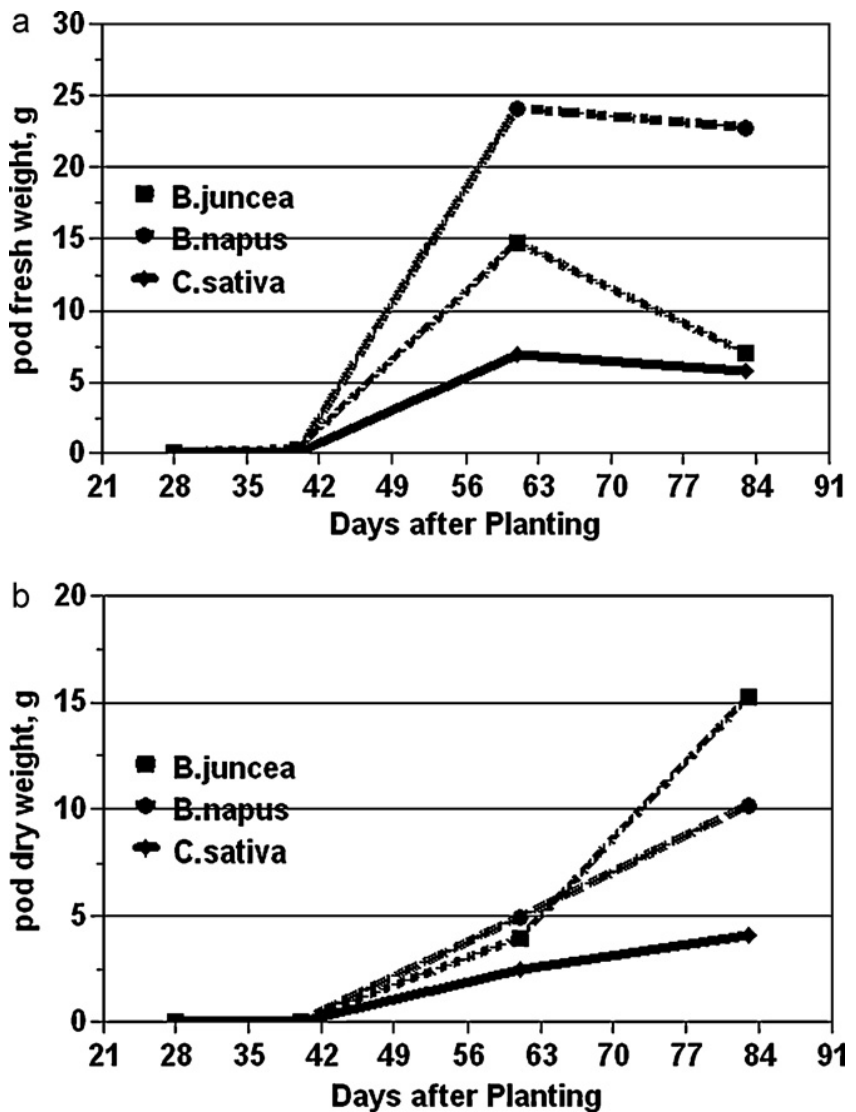

Fig. 4. Changes in pod fresh and dry weights from 40 to 82 DAP of brown mustard, canola and camelina at Scottsbluff. Each data point is the mean of 2005, 2006 and 2007, three years. The $\mathrm{LSD}_{0.05}$ for pod fresh weights was $0.1,4$, and 3 for 40,61 , and 82 DAP, respectively, and for pod dry weights, they were 2.5 and 4.1 for 61 and 82 DAP, respectively. rows. Unlike the canopy measurements, stem length grew slower and did not reach a plateau by 82 DAP although the rate of growth slowed between 61 and 82 DAP. The discrepancy may have been due to the onset of leaf senescence at 61 DAP followed by gradual defoliation.

Root weight of all three crops increased linearly from 28 to 61 DAP. The growth rate of camelina roots was about a fifth that of the Brassica. Therefore, camelina lagged significantly behind. The slow growth of the root system supports observations that irrigation and fertilization of all three of these crops are critical during the first six weeks for plant growth and suggest why these crops may not be suitable for dryland production in semi-arid and arid regions. Vine fresh weight increased rapidly between 28 and 40 DAP then leveled and gradually declined as plant senescence began to desiccate leaves. However, dry matter accumulation continued to 61 DAP as dry weight continued to increase while fresh weight remained the same or even declined. Vine dry weight, excluding pods, leveled at 61 DAP as the pods became the nutrient sink. This is evident as pods appeared after 40 DAP and their fresh weight increased rapidly to 61 DAP then leveled or gradually declined as the pods began to desiccate. Saseendran et al. (2010) reported the first appearance of pods at 50 DAP when canola was planted on 20 April 2006 while pod set took longer with earlier planting dates. Pavlista et al.(2011a) also reported that pod appearance took longer with earlier planting date. Pod dry weight increased from appearance to 82 DAP with canola and brown mustard accumulating dry matter at 2.5 and 3.5 times that of camelina, respectively. This observation would suggest that camelina would benefit most from earlier planting (Pavlista et al., 2011a). Saseendran et al. (2010) also reported that canola's biomass, which unfortunately was not defined, reached a maximum under full irrigation, $>120 \mathrm{~mm}$, at 90 DAP in 2005 and 80 DAP in 2006. If biomass means the dry weight of the whole above-ground plant (vine plus pod), then the biomass of the Brassica reported here had not reached their maximum by 82 DAP while that of camelina had. Note that plant dry weight excluding pods plateaued at 61 DAP while pods continued to accumulate dry matter.

Yields in 2006 did not significantly differ for the three crops. Oil content and fatty acid composition were similar to that reported earlier at this site (Pavlista et al., 2011a) and in the region for canola (Pavlista et al., 2011b). The fatty acid profiles of the brassica versus the camelina had significant differences as expected. The brassica crops were high in oleic acid content 61.7-68.0\%. Camelina had a large amount of linolenic acid compared to the brassica and significantly more saturates, $10.5 \%$, compared to $7.5 \%$ for the brassica. The higher level of unsaturation will make camelina oil more oxidatively unstable and the increased saturates will give the resulting biodiesel a higher cloud point than the brassica. Lastly, the importance of the fatty acid distribution of these crops was discussed earlier in Pavlista et al. (2011a).

\section{Conclusion}

The growth curves of brown mustard, canola and camelina differed considerably. Canola tended to weigh more than the other 
two crops while brown mustard tended to be larger. The transition of growth from roots to vines to pods was seen in all three crops. The three crops showed potential for oil production under irrigation in this region. These trials were conducted under conditions of total rainfall plus irrigation of near $200 \mathrm{~mm}$ which may be sub-optimal (unpublished data).

\section{Acknowledgements}

Authors wish to acknowledge the technical assistance of James Margheim, Ph.D., Eric Nielsen and Linda Manthey, and the financial support of Progressive Producers of Nebraska.

\section{References}

Angadi, S.V., Cutforth, H.W., McConkey, B.G., Gan, Y., 2004. Early seeding improves the sustainability of canola and mustard production on the Canadian semiarid prairie. Can. J. Plant Sci. 84, 705-711.

Angadi, S.V., Cutforth, H.W., Miller, P.R., McConkey, B.G., Entz, M.H., Brandt, S.A., Volkmar, K.M., 2000. Response of three Brassica species to high temperature stress during reproductive growth. Can. J. Plant Sci. 80, 693-701.

Baltensperger, D.D., Lyon, D.J., Burgener, P.A., Hein, G.L., Harveson, R.M., Yonts, C.D., Margheim, J.F., Frickel, G.E., Foster, G.J., 2004. Brown Mustard Production. U. Nebraska Coop Ext Circ \#04-183.

Boyles, M., Peeper, T., Stamm, M., 2006. Great Plains Canola Production Handbook. Kansas State U. MF-2734.
Changnon, S.A., Lamb, P., Hubbard, K.G., 1990. Regional climate denters: new institutions for climate services and climate-impact research. Bull. Am. Meteorol. Soc. 71, 527-537.

Chen, C., Jackson, G., Karnes, N., Wichman, D., Johnson, G., Johnson, D., 2005. Determining the feasibility of early seeding canola in the northern Great Plains. Agron. J. 97, 1252-1262.

Clark, B.J., Scheiber, L.L., 2008. A sloping land: an introduction. In: Scheiber, L.L. Clark, B.J. (Eds.), Archeological Landscapes on the High Plains. University Press of Colorado, Boulder, CO, pp. 1-16.

Dyer, J.M., Stymne, S., Green, A.G., Carlsson, A.S., 2008. High-value oils from plants. Plant J. 54, 640-655.

Johnston, A.M., Tanaka, D.L., Miller, P.R., Brandt, S.A., Nielsen, D.C., Lafond, G.F., Riveland, N.R., 2002. Oilseed crops for semiarid cropping systems in the northern Great Plains. Agron. J. 94, 231-240.

Ludlow, M.M., Muchow, R.C., 1990. A critical evaluation of traits for improving crop yields in water-limited environment. Adv. Agron. 43, 107-153.

Meyer, R., Belshe, D., O’Brien, D., Darling, R. (Eds.), 1999. High Plains Sunflower Production Handbook. Kansas State U. MF-2384.

Pavlista, A.D., Isbell, T.A., Baltensperger, D.D., Hergert, 2011a. Planting date and development of spring-seeded irrigated canola, brown mustard and camelina. Ind. Crop Prod. 33, 451-456.

Pavlista, A.D., Santra, D.K., Isbell, T.A., Baltensperger, D.D., Hergert, G.W., Krall, J., Mesbach, A., Johnson, J., O’Neil, M., Aiken, R., Berrada, A., 2011b. Adaptability of irrigated spring canola oil production to the US High Plains. Ind. Crop Prod. 33 $165-169$.

SAS Institute, 2003. SAS System for Windows. Release 9.1. SAS Institute Inc., Cary, NC.

Saseendran, S.A., Nielsen, D.C., Ma, L., Ahuja, L.R., 2010. Adapting CROPGRO for simulating spring canola growth with both RZWOM2 and DSSAT 4.0. Agron. J. 102, 1606-1621.

Vigil, M.F., Anderson, R.I., Beard, W.E., 1997. Base temperature and growing-degreehour requirements for the emergence of canola. Crop Sci. 37, 844-849. 